\title{
El desarrollo creativo en Educación Musical: del genio artístico al trabajo colaborativo
}

\author{
José Luis Aróstegui Plaza*
}

\section{Resumen}

Este artículo es una revisión de la literatura científica sobre el papel de la creatividad en la educación musical. Es éste un campo, el de la creatividad y el papel que ha de jugar en el desarrollo del currículo, que está cobrando cada vez más importancia, sin duda por la necesidad de dar una respuesta desde la educación a un mundo en constante proceso de cambio y en direcciones difíciles de prever en la actualidad. De las diferentes corrientes existentes, el enfoque que se desarrolla en este artículo se basa en el constructivismo y en la teoría sociocultural, al poner el énfasis en la creatividad y en la motivación a través de la actividad de los sujetos y en la importancia que tiene el trabajo en grupo para la comprensión de los procesos y resultados creativos y de ejecución musical. Al final se concluye que el aprendizaje musical ha de basarse en la creatividad y que ésta, a su vez, se aprende a través de la interacción social.

Palabras clave: creatividad, educación musical, constructivismo.

\section{Creative development in music education: from artistic genius to collaborative work}

\begin{abstract}
This article makes a review of the literature on the role of creativity in musical education. The field of creativity and its role to play in developing the curriculum is becoming increasingly important. The emergence of this topic is likely due to the need of giving a response from education to a world in constant change and in directions difficult to predict at present. Among the different existing trends on creativity research, this article is based on constructivism and sociocultural theory, emphasizing on creativity and motivation through subjects' activity and the importance of collaborative work to understand the processes and outcomes of creative and musical performance. In the end, the conclusion is that musical learning should be based on creativity and this, in turn, is learned through social interaction.
\end{abstract}

Keywords: creativity, music education, constructivism.

* Profesor Facultad de Ciencias de la Educación - Universidad de Granada, España. 


\section{José Luis Aróstegui Plaza}

\section{Artículo}

La creatividad empezó a ser objeto de estudio hace unos cincuenta años, poco en comparación con otras ramas de la psicología. Lo mismo puede decirse del estudio de la creatividad musical, que comenzó hace treinta. La razón de un interés tan reciente probablemente radique en la dificultad para definirla y evaluarla. Resulta paradójico, no obstante, esta exigua investigación en comparación con la cantidad de materiales y metodologías existentes encaminados al desarrollo de la creatividad y la importancia que se le da a la misma en educación. Los métodos de Dalcroze, Orff, Willems, y Schaffer, entre otros autores, han propuesto actividades y metodologías encaminadas a la composición y a la improvisación que, sin embargo están en realidad basadas más en la intuición que en una fundamentación científica sobre la creatividad musical.

Si aceptamos que el profesorado de música, sobre todo en niveles educativos obligatorios, además de dedicarse a la producción musical en sus diversas facetas, debe desarrollar la autonomía del alumnado y la toma de decisiones a partir de sus propios criterios estéticos, convendremos que el papel de la creatividad es clave en el desarrollo de un currículo así entendido, de ahí que uno de los objetivos de la inclusión de la educación artística en la educación obligatoria sea "la capacidad que genera la música, la plástica y la dramatización para el desenvolvimiento de la aptitud creativa" (ORIOL, 2001, p. 15).

En este artículo pretendo hacer una revisión de la literatura científica sobre el papel de la creatividad en la educación musical. Es éste un campo, el de la creatividad y el papel que ha de jugar en el desarrollo del curríulo, que está cobrando cada vez más y más importancia, sin duda por la necesidad de dar una respuesta educativa a un mundo en constante proceso de cambio y en direcciones difíciles de prever. De las diferentes corrientes existentes, el enfoque que voy a desarrollar se basa en el constructivismo y en la teoría sociocultural, al poner el énfasis en la creatividad y en la motivación a través de la actividad de los sujetos (v.g. PIAGET, 1984 Y GARDNER, 1994, entre otros) y en la importancia que tiene el trabajo en grupo para la comprensión de los procesos y resultados creativos y de ejecución musical (MIELL, LITTLETON Y ROJAS-DRUMMOND, 2008). La idea central del constructivismo puede resumirse en que el aprendizaje es más efectivo cuando el sujeto es puesto en acción antes que recibiendo pasivamente información (KAFAI Y RESNICK, 1996). La idea subyacente es dejar de estar centrados en el contenido y en la actividad del profesorado para pasar a darle el protagonismo al alumnado como constructor colaborativo de su aprendizaje.

\section{Definición de creatividad y creatividad artística}

Las distintas tendencias de la psicología generalmente están de acuerdo en que una persona creativa es aquélla que genera ideas relativamente nuevas, 
apropiadas y de alta calidad (STERNBERG, 1988). Este mismo autor, junto con Todd Lubart (STERNBERG y LUBART, 1997), define un producto como creativo cuando es original y apropiado:

\begin{abstract}
Un producto es original cuando estadísticamente es poco común, cuando es diferente de los productos que otras personas tienden a producir. Un producto es original cuando no es predecible, y puede provocar sorpresa en el espectador porque la cadena lógica es algo más que el siguiente eslabón lógico [...]. La originalidad percibida de un producto depende también de la experiencia anterior del público.Un producto debe desempeñar también cierta función, debe ser una respuesta apropiada a cierta pregunta, tiene que ser útil. Existe una gama de conveniencia que va desde lo que es mínimamente satisfactorio a lo que es una solución radicalmente buena de las limitaciones impuestas por el problema. Algo que sea original pero que no satisfaga las limitaciones del problema que se tiene entre manos no es creativo, es lo que diríamos curioso (y por consiguiente, irrelevante). (p. 28)
\end{abstract}

Esta funcionalidad no implica necesariamente una aplicación pragmática, sino que puede consistir en dar respuesta a un sentimiento interior a través de la creación artística, por ejemplo. Sternberg y Lubart aportan otras dos características de un producto creativo, si bien no las considera conditio sine qua non de una obra creativa: la calidad o complejidad con que está realizado, y la importancia que el público le dé. En cualquier caso, estos cuatro elementos, tal y como los definen estos autores, comparten una característica común: dependen de la concepción del público, no siendo por tanto algo interno al individuo, aspecto éste en el que ya difieren las distintas corrientes psicológicas.

Vigotsky (1996), por su parte define la actividad creadora como "toda realización humana creadora de algo nuevo, ya se trate de reflejos del algún objeto del mundo exterior, ya de determinadas construcciones del cerebro o del sentimiento que viven y se manifiestan sólo en el propio ser humano" (p. 7). Considera que la conducta del ser humano es de dos tipos: reproductora, limitándose fundamentalmente a repetir con mayor o menor precisión algo ya existente, y creadora, cuando imaginamos el futuro de alguna manera, una idea, una imagen, etcétera. La clave de la creatividad está por tanto en la imaginación, de ahí la relación que encuentra entre creatividad y juego infantil.

Aunque la definición de creatividad de Vigotsky es general, su trabajo se dedica a la creatividad en el arte. Cuatro son los principios que encuentra para la creatividad artística que este autor considera en relación con cada nivel de desarrollo, de modo que a cada periodo infantil le corresponde su propia forma de creación. 


\section{José Luis Aróstegui Plaza}

1. La actividad creadora de la imaginación se encuentra en relación directa con la riqueza y la variedad de la experiencia acumulada por el ser humano. Cuanto más rica sea, tanto mayor será el material del que dispone la imaginación. De aquí la conclusión pedagógica de ampliar la experiencia del niño si queremos proporcionarle base suficientemente sólida para su actividad creadora.

2. Existe siempre una relación entre los productos imaginados y determinados fenómenos de la realidad. La imaginación no se limita a reproducir lo asimilado en pasadas experiencias, sino que, partiendo de ellas, crea nuevas combinaciones. Esta vinculación sólo es posible gracias a la experiencia ajena o social. Así es cómo, por ejemplo, podemos imaginarnos un cuento que se desarrolla en el desierto sin que hayamos estado necesariamente allí. La imaginación trabaja guiada por experiencias ajenas.

3. La emoción también está presente, en un doble sentido. Por un lado, todo sentimiento tiende a manifestarse en determinadas imágenes concordantes con ella, "como si la emoción pudiese elegir impresiones, ideas, imágenes congruentes con el estado de ánimo que nos dominase en aquel instante" (ibídem, p. 21). Es lo que Vigotsky denomina la "ley del signo emocional común": todo lo que nos causa un efecto emocional coincidente tiende a unirse entre sí pese a que no se vea entre ellos semejanza alguna ni exterior ni interior. Se comprende fácilmente que esta influencia del factor emocional debe propiciar el surgimiento de agrupaciones totalmente inesperadas, brindando un campo casi ilimitado para nuevas combinaciones ya que el número de imágenes que poseen un sello emocional idéntico es muy grande. Esta relación entre imaginación y emoción es recíproca, pues, por otro lado, "todas las formas de la representación creadora encierran en sí elementos afectivos" (ibídem, p. 23). Es lo que Vigotsky llama la "ley de la representación emocional de la realidad", la cual explica por qué causan en nosotros impresión tan honda las obras de arte creadas por la fantasía de sus autores. Esto es bastante claro en música, donde los estímulos sonoros que llamamos música puede desembocar en profundas emociones (p. 24).

4. Una última forma de elaboración entre fantasía y realidad es cuando se crea algo totalmente nuevo, no existente en la experiencia previa ni parecido a nada existente previamente, estableciéndose por tanto un vínculo práctico con la realidad, como en el caso de un máquina o un invento. En este caso, el aspecto intelectual y el emocional resultan necesarios por igual.

Esta última cuestión lleva a este autor a preguntarse para qué es útil o necesario el arte, a lo que da dos respuestas. La primera respuesta que da es lo que denomina la "función biológica del arte" (Vigotsky, 1970). Aquella conducta que no es realizada por el individuo produce inestabilidad en éste. El arte sería el 
instrumento para lograr este equilibrio en el medio ambiente de nuestra conducta. Pero esta descarga emocional es algo que compartimos con los animales superiores; lo que nos distingue y eleva la emoción a la categoría estética es la facultad de organizar reacciones, eligiendo los medios para exteriorizarlas, para que mediante la superación de ese sentimiento consecuencia de una acción no realizada se realice el arte, se convierta el sonido en música.

La segunda es de carácter social, pues las obras las obras de arte influyen enormemente sobre la conciencia social, gracias a su lógica interna (VIGOTSKY, 1996). La obra de arte no es una aglutinación de imágenes de la fantasía sin orden alguno, sino que siguen la lógica interna de las imágenes que desarrollan, la cual viene condicionada por el vínculo que establece la obra entre su propio mundo y el mundo exterior.

Aunque realizados desde enfoques distintos, la definición general de creatividad de Sternberg y Lubart y la de creatividad artística de Vigotsky comparten tres rasgos básicos: es algo nuevo, práctico, y depende del contexto social, por lo que puede decirse que una persona creativa es aquélla que realiza obras nuevas que son aceptadas en función de su utilidad para un determinado grupo en un momento dado.

Con respecto a la creatividad musical, Webster (1992) realizó una revisión de la literatura existente sobre investigación en para el primer Manual de Investigación en Enseñanza y Aprendizaje Musical (en Colwell, 1992). Dicha revisión la ha mantenido actualizada, estableciendo una clasificación de las investigaciones disponibles (WEBSTER, 2002b). Este autor encuadra las investigaciones sobre creatividad musical en tres grupos:

1. Trabajos teóricos, proporcionando fundamentos filosóficos o psicológicos, así como una revisión sobre modelos en creatividad y estudios históricos;

2. Aplicaciones prácticas, es decir, trabajos con información sobre experiencias prácticas pero que no derivan de evidencias empíricas;

3. Trabajos empíricos, con trabajos obtenidos a partir de la medición o de la observación.

Este tercer grupo es el más complejo, con estudios que analizan estrategias de enseñanza, diseños evaluativos, uso de las tecnologías, relaciones entre variables relacionadas o no con la música, y el alcance real de la experiencia creativa. El estudio de las condiciones a partir de las cuales se permite o no la creatividad es una tendencia reciente y está aumentando con rapidez, al igual que sucede con el estudio de la creatividad y su relación con la tecnología y con las estrategias de enseñanza. 


\section{José Luis Aróstegui Plaza}

\section{El pensamiento creativo}

De entre las distintas corrientes que investigan la creatividad musical, a continuación abordaré la denominada pensamiento creativo. Escojo precisamente ésta por tres razones. La primera, porque hablar de pensamiento creativo en vez de creatividad implica poner el acento en el proceso que lleva a la obra, idea o producto que valoramos como creativo o no. Tal vez por este motivo, es ésta la corriente que a mi parecer tiene mayor aplicación al ámbito educativo, segunda razón para escoger precisamente este tópico. Por último, encuentro que, aun con sus diferencias, el pensamiento creativo es un concepto empleado tanto por los enfoques experimentales como por los contextuales anteriormente mencionados.

Webster (1990) define el pensamiento creativo como "la implicación de la mente en el proceso activo de estructuración de pensar en sonidos con el propósito de producir algún producto que es nuevo para su creador" (p. 26). A partir de aquí, este autor considera que el pensamiento creativo es un proceso dinámico de alternancia entre el pensamiento divergente y el convergente, de ideas que en ocasiones se separan del modelo seguido o que se adhieren a él, respectivamente, y que se mueven en fases de alternancia gracias a ciertas capacidades de la persona, algunas innatas, otras aprendidas, y que, desarrolladas en determinadas condiciones, desembocan en la consecución de un producto.

La mayoría de los investigadores están de acuerdo en que el pensamiento creativo está canalizado por un problema y por la necesidad de solucionarlo. Mientras que en Ciencias Naturales, Ingeniería, etc., el problema es algo muy concreto (ya sea la formulación de una nueva teoría o el diseño de un teléfono móvil, por ejemplo), En el caso del arte, el problema es más una "fuerza" la que conduce a una solución creativa. Más concretamente en música, la respuesta de esta fuerza se canaliza hacia la composición, la interpretación / improvisación, o la audición y análisis, todos ellos entendidos como los productos a conseguir que canalizan el proceso de creación y que son a la vez los resultados que proceden del pensamiento creativo.

En ir de la intención de crear un producto hasta el resultado, el proceso de pensamiento está en constante interacción entre dos niveles cualitativamente distintos de pensamiento. El pensamiento divergente en música supone pensamiento imaginativo, explorando las posibilidades de la expresión musical para sopesar diferentes posibilidades; una frase rítmica o melódica, un acorde, un timbre, o incluso secuencias musicales más complejas constituyen ejemplos de pensamiento musical primero imaginados y, probablemente, después tocados en un instrumento. Estas "acciones primitivas" o rudimentarias son parte de la fase de exploración que con frecuencia caracteriza el inicio del pensamiento creativo. Este pensamiento es básicamente divergente, aunque a medida que se van refinando las ideas, y puede que más tarde rechazadas, aparecerán nuevos periodos de divergencia más sofisticados. 
Por su parte, el pensamiento convergente es más lineal y analítico. Aquí las decisiones estéticas están más elaboradas y las acciones se convierten en entidades que están lejos de ser primarias. El pensamiento en este caso es más discriminante y es dirigido por un plan emergente que puede ser consciente o inconsciente. Este tipo de pensamiento es más frecuente que suceda en la fase final del proceso creativo, pero no siempre ocurre así. En cualquier caso, la clave creativa está en la interacción entre pensamiento convergente y divergente.

Este flujo entre ambos modos de pensamiento es facilitado por una serie de condiciones que lo facilitan y que en gran parte escapan del influjo de la educación formalizada. Son igualmente importantes un conjunto de capacidades que se suelen considerar como propias del ámbito escolar. Tanto las condiciones como las capacidades facilitan el pensamiento convergente y divergente, y además los dirigen.

Es importante la consecución de un producto como consecuencia del proceso creativo, pues ésta es la diferencia entre pensamiento creativo y fantasía. Los productos musicales pueden ser composiciones escritas, producciones de obras previamente compuestas o improvisadas, y análisis tanto escritos como representaciones mentales de la música que escuchamos.

\section{El pensamiento creativo en el aula de música}

El proceso creativo es significativo para el pensamiento musical del alumnado de educación musical. Dejando aparte la razón obvia de la necesidad de conocer cómo son los procesos del contenido musical acordes con un currículo centrado en el proceso, encuentro otras dos motivos para abordar esta cuestión. En primer lugar, una experiencia educativa tiene que ser significativa para el alumnado, tiene que percibir que lo que aprende es beneficioso para sus vidas. Necesitan igualmente tener un sentimiento de propiedad de lo que sucede en el aula, que sus ideas son valoradas en el contexto educativo y que su trabajo y el que les ofrece la escuela conecta con su vida más allá de los límites del centro. De acuerdo con Wiggins (2002) una forma de conseguir tal significatividad es acercando el proceso creativo al aula de música. En segundo lugar, y siguiendo a Gardner (1995) y su teoría de las inteligencias múltiples, todas las personas tienen diversos modos de pensar. Una formación integral del alumnado debiera ofrecer oportunidades para su crecimiento de tal modo que pueda pensar de múltiples modos. El pensamiento musical es una de esas formas de inteligencia que las personas tienen. El proceso de creación musical permite al alumnado implicarse en el pensamiento musical de manera significativa para cada uno.

La capacidad para involucrarse en el pensamiento musical es básico para comprometerse con la música y comprenderla. Hasta qué punto una persona comprende unos sonidos en relación con otros y además en el contexto en el 


\section{José Luis Aróstegui Plaza}

que se producen determina su mayor o menor capacidad para interesarse por la música y por el pensamiento musical. Gardner (1995) define la inteligencia musical como la sensibilidad a la estructura de la música que le permite a un individuo tomar decisiones apropiadas a la música de acuerdo a su experiencia, que incluye la sensibilidad a las propiedades musicales, a las interrelaciones entre ideas musicales, y las expectativas sobre qué le da sentido a la música. El pensamiento musical, por tanto, es inteligencia musical en acción.

En una clase de música, el alumnado piensa musicalmente cuando escucha, cuando toca o canta una pieza musical, y cuando compone. En cualquiera de las tres actividades, necesitan que el estudiante ponga en uso su entendimiento musical y sus contextos. A la hora de reproducir una pieza, podemos interpretar una pieza original o ya escrita por otros. En ambos casos el proceso es creativo, pues comprende la versión personal de esa obra y el darle sentido a la misma (WIGGINS, 2002). La audición es un proceso creativo en tanto que las personas que están escuchando e interpretando los significados de la obra la están re-creando en sus mentes a medida que escuchan, y por tanto trayendo a colación a la experiencia de audición para hacerla significativa. A la hora de componer una obra musical o de improvisar, los implicados están generando nuevas ideas musicales que luego desarrollan y ponen en contexto de maneras nuevas y originales. Cualquiera que sea la actividad de interpretación, audición o composición, la experiencia musical previa de cada persona, lo complejo de su capacidad para pensar en sonido, y su mayor o menor capacidad para percibir esos sonidos en contexto determinarán la sofisticación o simplicidad de la experiencia musical y del producto obtenido. Por tanto, la valoración y evaluación de los productos creativos del alumnado y de los procesos para elaborarlos puede darnos gran cantidad de información del pensamiento musical y su comprensión del hecho musical.

Para Wiggins (ibídem), la esencia del pensamiento musical de los niños es holístico, lo que puede reflejarse en prácticamente cualquier actividad que realizan. En lo referente a la producción musical, a la hora de tocar una melodía de oído, repetirán la melodía desde el principio:

Por ejemplo, cuando un estudiante está tocando mal una frase al final de la pieza repetidamente, este alumno invariablemente volverá al principio de la melodía como parte del proceso para arreglar el problema, aunque esté en la parte final. Si intento enseñarles sólo la última frase, parecen incapaces de empezar desde ahí, necesitan ir al principio para comprender cómo solucionar el problema del final. Es como si la capacidad para concebir sólo una parte de la melodía supusiera un proceso conceptual más sofisticado que el de tocarla entera. Si observamos cuánto de la enseñanza musical suele centrarse en fragmentos melódicos, podremos ver cuán importante es para el profesorado comprender la perspectiva de su alumnado (p. 81). 
La misma concepción holística del pensamiento musical de los más pequeños se da en composición e improvisación. Wiggins encuentra que cuando el alumnado compone en grupo sin dirección de adultos, sus decisiones iniciales con frecuencia reflejan elementos organizativos globales, tales como la textura, la forma, y el carácter de la agrupación musical. Además, cuando empiezan a preparar el material temático, siempre lo conciben por bloques (DAVIDSON y WELSH, 1988), con frecuencia estructurado por un alumno de alguna manera antes de que sea tocado o cantado, también frecuentemente creando esa nueva frase teniendo en cuenta las ideas de los compañeros de grupo, y en ocasiones cantando o marcando rítmicamente a la vez que los otros compañeros tocan el tema por primera vez. Cuando la composición se hace sin la ayuda de instrumentos, es frecuente cantar fragmentos largos desde el primer intento, si bien suelen probarse diversas variantes antes de llegar al resultado final. En cualquier caso, la idea inicial se estructura como frase musical y se completa con su texto y sus articulaciones expresivas (SLOBODA, 1985).

Durante todo el proceso, el alumnado hace constantes referencias a las ideas musicales que suenan "bien" o no de acuerdo a preferencias individuales o grupales sobre cómo debiera sonar el resultado final. A medida que la obra va tomando forma, las nuevas ideas que van surgiendo son consideradas o no de acuerdo al carácter general de la obra en ese momento de preparación. Cuando algunos alumnos de los que trabajan en una composición grupal se dedican a trabajar una idea en concreto, con frecuencia piden a sus compañeros que lo escuchen entero para comprobar si lo que están haciendo encaja con las ideas de los demás. Una cuestión clave en el proceso de composición de la pieza parece ser la necesidad de relacionar las ideas individuales a la visión del grupo. Es la percepción del trabajo en realización lo que le da significado a las ideas musicales.

Las ideas musicales no son la única cuestión que el alumnado percibe globalmente, sino que en muchos sentidos posee una comprensión común del trabajo que desarrolla que es más amplia que las ideas de cada individuo por separado; la visión del grupo es mayor que las de los individuos que la componen (BEALS, 1998). Los componentes de un grupo juzgan el mérito y lo apropiado de las ideas individuales de acuerdo a la visión compartida de cómo marcha la obra que están preparando, percepción grupal que refleja sus influencias culturales, incluidas las de los medios de comunicación de masas y las músicas propias de su grupo cultural. En la creación grupal, nadie toca o canta como quiere, sino en respuesta al trabajo que está realizando el grupo (SAWYER, 2008), evidenciando, por un lado, que estructura y libertad van de la mano, y la importancia del trabajo colaborativo en el pensamiento creativo en contraposición a la visión tradicional de percibir el trabajo creativo como el de personas aisladas, al menos en el campo musical y artístico. El trabajo de composición o de improvisación realizado entre iguales depende de los supuestos de partida que comparta el grupo, de la naturaleza de la tarea encargada por el profesor, de la experiencia compartida al desarrollar el currículo musical, y de la música escuchada fuera de la escuela (WIGGINS, 2000). 


\section{José Luis Aróstegui Plaza}

\section{A modo de conclusión: creatividad y contexto de aprendizaje}

Tres son en mi opinión las principales características y cambios que ha experimentado el estudio de la creatividad en general y musical en particular:

1. Una transición de un estudio psicológico centrado en las capacidades de la persona a una perspectiva también psicológica en la que se le presta un interés cada vez mayor al contexto social.

2. Un cambio de interés del producto al proceso creativo.

3. Una transición desde una perspectiva más psicométrica y fenomenológica a otra más cualitativa.

Parece comprensible que se haya prestado atención a estas características: la creatividad es un rasgo de la personalidad del individuo; implica un producto; $y$, por último, históricamente ha habido un interés por encontrar leyes universales que expliquen los fenómenos utilizando exclusivamente los métodos propios del positivismo. Parece igualmente comprensible la evolución cuando a medida que se ha ido dejando de buscar leyes universales, se ha ido buscando la explicación del hecho creativo en lo particular; cuando se le ha prestado atención a cómo se llega a tal producto en vez de al producto en sí mismo; y, en definitiva, cuando se ha abandonado un concepto de artista como genio para ir conformando otro en el que la creatividad deja de ser un proceso de "caja negra" misterioso, inexplicable y excepcional, para convertirse en una capacidad de todos los individuos que puede desarrollarse creando el contexto propicio para ello.

Weisberg (1995) ofrece un concepto de la creatividad cuyo propósito es desmitificar una serie de creencias sobre la creatividad que suelen darse por supuestas: básicamente, que experimentamos un repentino impulso creador, sin que tengamos clara conciencia de cómo pudo acontecernos, es decir, que "nos viene la inspiración" desde fuera e inesperadamente, y que el genio creador logra sacar algo en claro donde los demás no ven nada, es decir, depende de la persona en sí misma, sin que sea posible aprender esta capacidad que o se tiene, o no se tiene. Robert Weisberg propone un enfoque en el que la creatividad se aprende como consecuencia de la acumulación de experiencias en el que pasa a contemplarse como una actividad resultante de procesos de pensamientos ordinarios de individuos ordinarios:

En nuestros experimentos, las soluciones originales se obtuvieron evolutivamente, merced al trabajo consciente del sujeto sobre el problema. Lo típico era que el sujeto tratase en primer lugar de aplicar directamente al problema conocimientos procedentes de experiencias pasadas; de ordinario, el diseño de los problemas lograba frustrar tales intentos, obligando al sujeto a modificar su solución anterior para ajustarse a los requisitos del problema. Estas modificaciones iban siendo 
El desarrollo creativo en Educación Musical: del genio artístico al trabajo colaborativo

alentadas por la adquisición de información adicional. Aunque el proceso de resolución solía comenzar con la aplicación directa (e infructuosa) de experiencias pasadas, la solución inicial podía ir evolucionando hasta convertirse en algo nuevo y apropiado al caso, es decir, en una solución creativa del problema. (p. 14-15)

Este planteamiento tiene consecuencias para la educación, a saber: que la capacidad de creación se aprende, ya sea científica, artística, o de cualquier otro tipo, pudiendo desarrollarse o no en razón del contexto del aprendizaje y de la naturaleza de la tarea a realizar. En la escuela, es el profesor quien suele determinar las actividades a realizar, y dicha tarea está influida por su percepción y conocimiento de cómo es el procedimiento que emplean sus estudiantes para llevarlo a cabo. A fin de preparar trabajos de composición e improvisación que fomenten y permitan el pensamiento musical, es del todo necesario que el profesorado comprenda la visión global y holista del alumnado tanto de las ideas musicales como de su proceso de trabajo, más aún cuando el docente es un condicionante importante para que el trabajo del estudiante se considere creativo o no (ODENA, 2005).

Esto significa que las tareas de corte analítico, como componer a partir de un ritmo, o escribir una pieza utilizando determinadas notas, las va a ver el alumnado como un rompecabezas que ha de ser resuelto antes que como una creación musical, pues no requiere utilizar y desarrollar el pensamiento musical, sino resolver un problema de acuerdo a determinadas reglas analíticas, independientemente de cómo suene y de la musicalidad que tenga. Un trabajo de composición en el aula no es un problema de notación musical, a no ser que el alumnado esté capacitado para concebir en su cabeza tales ideas desde la escritura musical convencional, es decir, escuchar mentalmente ideas musicales leyendo directamente desde la partitura. Sin embargo, lo objetivo, los parámetros del sonido y su notación, suelen acabar convirtiéndose en la tarea a la que le dedica mayor tiempo el profesorado. Si componer es crear ideas musicales nuevas, entonces las actividades a este respecto que se realicen en el aula han de permitir y ayudar a este proceso; las actividades creativas han de estar hechas de tal manera que permitan el fluir de las ideas musicales.

El profesorado no debiera restringir a determinadas alturas o ritmos lo que el alumnado puede utilizar para componer o improvisar, pues éste no suele ser consciente de qué alturas y ritmos está usando, sino cantando mentalmente. Si se les impide usar determinados sonidos o duraciones, puede que sean incapaces de materializar las ideas musicales que llevan dentro. Esto no significa que estas actividades sean totalmente libres para así dejar que fluya el artista que llevan dentro; por el contrario, puesto que el proceso de creatividad del alumnado implica el desarrollo de un material temático dentro de un contexto, parece que el mejor modo de favorecer la creatividad es tratando con los parámetros de ese contexto, no los de la música. Si el profesorado tiene en 
cuenta las circunstancias del entorno, entonces el alumnado es libre para poder desarrollar sus propias ideas musicales, aquellas que encuentren más adecuadas para ese contexto.

Al tener en cuenta las circunstancias contextuales, el profesorado puede pedir al alumnado, por ejemplo, componer o improvisar con determinada textura, compás, o escala. También le podría pedir desarrollar una pieza que tenga determinados contrastes dinámicos, de tempo, articulación, timbre o gama. Se le puede pedir que creen una pieza musical que tenga determinado carácter o que suscite determinada reacción en quien la escuche (de miedo, tranquilidad, agitación, etc.). A la hora de llevar a cabo cualquiera de estas tareas creativas, el alumnado probablemente se sentirá libre para concebir y desarrollar ideas temáticas globales que situarán en contexto, y a buen seguro encontrarán unas ideas más apropiadas para unas circunstancias, y otras para otras. La resolución de problemas creativos realizados de esta manera parece adecuarse mejor al modo de pensamiento musical que es más natural a los más pequeños.

El permitirles trabajar de este modo más libre con el sonido para generar sus propias composiciones, a buen seguro hará que el alumnado se sienta protagonista de la acción educativa y como que la música elaborada es de ellos, se convierte en una experiencia significativa y conectada a sus vidas. Cuando el alumnado puede desarrollar sus propias ideas de este modo, necesariamente habrá de saber que se aprecian en clase sus ideas y su música, consiguiendo por tanto que las experiencias de aprendizaje musical se conviertan en valiosas y significativas para cada estudiante.

\section{Referencias}

BEALS, D. E. Reappropriating Schema: Conceptions of Development from Bartlett and Bakhtin. Mind, Culture, and Activity: An International Journal, 5 (1), 3-24, 1998.

DAVIDSON, L. WELSH, P. From Collections to Structure: the Developmental Path of Tonal Thinking. In: J. A. Sloboda (Ed.). Generative processes in music: The psychology of performance, improvisation, and composition. Oxford: Clarendon Press, 1988.

GARDNER, H. Educación artística y desarrollo humano. Barcelona: Paidós, 1994. 1995.

Inteligencias múltiples: la teoría en la práctica. Barcelona: Paidós,

KAFAI, Y.; RESNICK, M. (Ed.) Constructionism in practice: designing, thinking, and learning in a digital world. Mahwah: Lawrence Eribaum, 1996.

MIELL, D.; LITTLETON, K.; ROJAS-DRUMMOND, S. Music Education: A site for collaborative creativity - Editorial Introduction. International Journal of Educational Research, 47(1), 1-2, 2008. 
ODENA, O. Creatividad en la educación musical. Teoría y percepciones docentes. Eufonía, 35, 82-94, 2005.

ORIOL, N. Estética y creatividad en la educación ante el nuevo milenio. In: N. Oriol (ed.): La educación artística, clave para el desarrollo de la creatividad. Madrid: M. E. C. D, 2001.

PIAGET, J. Psicología del niño. Madrid: Morata, 1984.

SAWYER, R. K. Learning from music collaboration. International Journal of Educational Research, 47 (1), 50-59, 2008.

SLOBODA, J. A. The musical mind. Oxford: Oxford University Press, 1985.

STERNBERG, R. J. (Ed.) The nature of creativity: contemporary psychological perspectives. Nueva York: Cambridge University Press, 1988.

STERNBERG, R. J.; LUBART, T. I. La creatividad en una cultura conformista. Un desafío a las masas. Barcelona: Paidós, 1997.

VIGOTSKY, L. S. Psicología del arte. Barcelona: Barral, 1970.

La imaginación y el arte en la infancia. Madrid: Akal, 1996.

WEBSTER, P. Conceptual Bases for Creative Thinking in Music. In: J. Peery, I. Peery, y T. Draper (Ed.). Music and child development. Nueva York: SpringerVerlag, 1987. 28, 1990 .

Creativity as creative thinking. Music Educators Journal, 76 (9), $22-$

Research on creative thinking in music: The assesment literature. In: R. Colwell (Ed.). Handbook of research on music teaching and learning. Nueva York-Toronto: Schirmer Books-Maxwell Macmillan, 1992.

Creative thinking in music: Advancing a model. In T. Sullivan y L. Willingham (Ed.). Creativity and music education. Edmonton: Canadian Music Educators' Association National Office, 2002.

WEISBERG, R. W. Creatividad: el genio y otros mitos. Barcelona: Lábor, 1995.

WIGGINS, J. H. The nature of shared musical understanding and its role in empowering independent musical thinking. Bulletin of the Council for Research in Music Education, 143, 65-91, 2000.

Creative Process as Meaningful Musk Thinking. In: T. Sullivan y L. Willingham (Ed.). Creativity and music education. Edmonton: Canadian Music Educators' Association National Office. 2002. 


\section{José Luis Aróstegui Plaza}

\section{Correspondência}

José Luis Aróstegui Plaza - Facultad de Ciencias de la Educación, Campus de Cartuja, s/n 18071 Granada, Espanha.

E-mail: arostegu@ugr.es

Recebido em 28 de agosto de 2011

Aprovado em 21 de outubro de 2011 